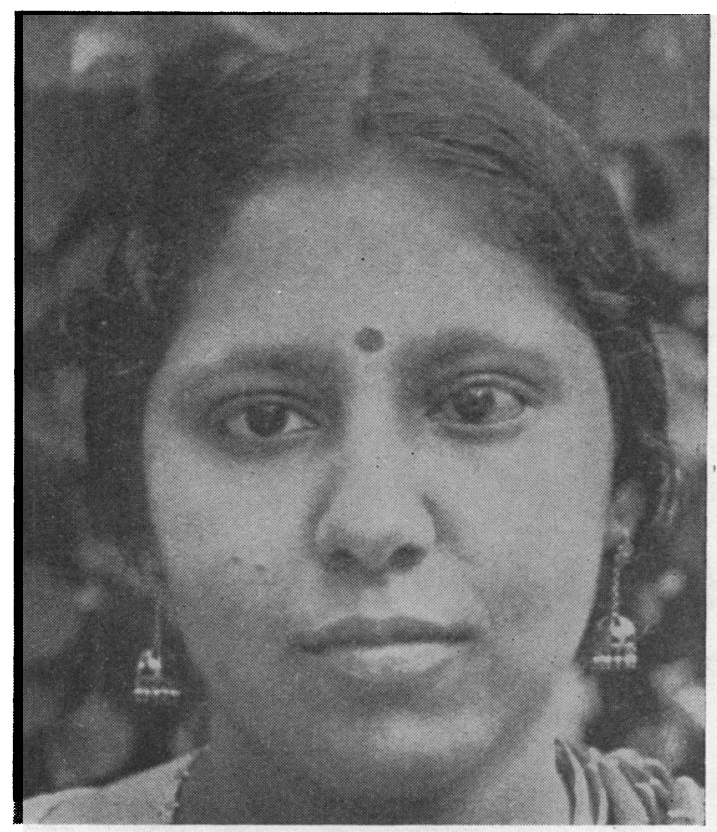

FIG 2.

After the insertion of painted contact glass.

The two photos clearly indicate the difference of the cosmetic effect and it is hoped that the publication of this case of mine will draw the attention of ophthalmologists to the cosmetic use of contact glasses.

\title{
STENOPAEIC SPECTACLES
}

BY
A. L. Young
LONDON

THE illustration shows a type of stenopaeic spectacle designed to overcome the disadvantage of present forms, in which the apertures are fixed in position, and may not be at the requisite interpupillary distance of the patient for whom they are required.

After diathermy operations for detached retina, when stenopaeic spectacles are worn, it is important, if the eyes are to be kept at rest, for the interpupillary distance to be correct for that particular 
patient, and after certain operations for squint it may be of advantage to be able to vary the relative position of the apertures for different patients.

In this new type there are two discs back to back which can be rotated independently of each other. Each disc is perforated by a curved slit, the aperture being produced by the overlapping of the slits. By a suitable manoeuvre, it is possible to place the aperture in any position on the disc save in the exact centre, an

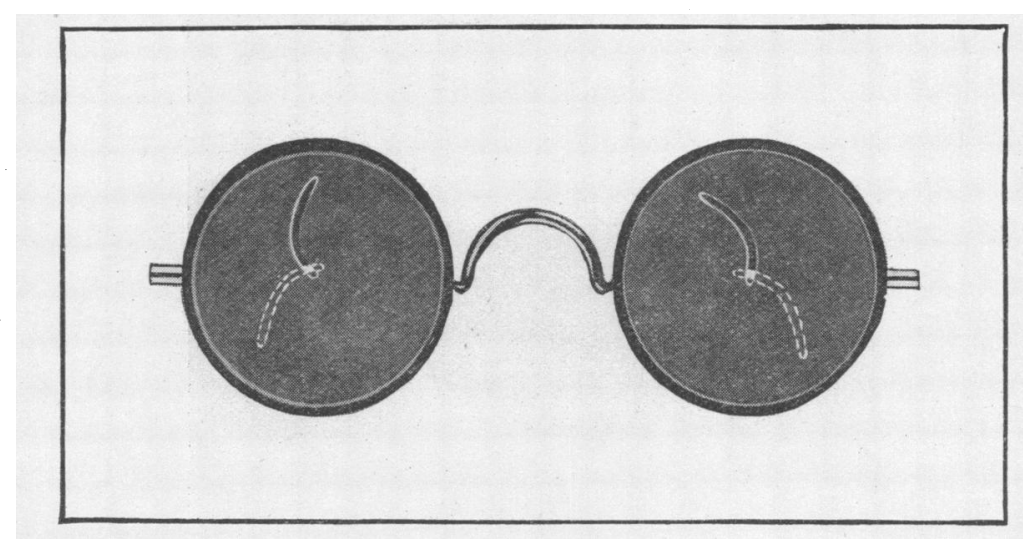

apparent disadvantage which can be overcome by de-centring an equal amount in each disc. Thus a vertical as well as a horizontal correction may be made. It is also possible, of course, to obliterate the aperture should only one be required.

The slits are at present made $2 \mathrm{~mm}$. in width. Rotation is facilitated by lightly smearing the opposing surfaces of the discs with vaseline; they are sufficiently firmly gripped by the rims to prevent accidental movement.

The spectacles have been made by, and are obtainable from, Messrs. Clement Clarke of Wigmore Street.

\section{ANNOTATION}

\section{Blindness in Great Britain}

Some interesting figures were supplied by the Minister of Health in moving, in the House of Commons, the second reading of the Blind Persons Bill on November 11, 1937. He stated that the total number of blind persons registered in England, Scotland and Wales was about 78,000 . Of these approximately 57,000 were aged 